\title{
Emphasizing a Service Phase Perspective for Machine Manufacturers Seeking Digital Servitization - a Taxonomy for Industrial Service Phases
}

\author{
Alexander Kreyenborg \\ TU Dortmund University \\ Alexander.Kreyenborg@tu-dortmund.de \\ Jonas Eichholz \\ TU Dortmund University \\ Jonas.Eichholz@tu-dortmund.de
}

\author{
Daniel Hefft \\ TU Dortmund University \\ Daniel.Hefft@tu-dortmund.de \\ Can Azkan \\ Fraunhofer ISST \\ Can.Azkan@isst.fraunhofer.de
}

\begin{abstract}
The ongoing shift to solution-oriented business models and growing digitalization lead to an increasing importance of services in manufacturing industry. Machine manufacturers in particular struggle to grasp the extent of transformational impact enabled or required by service developments. This is due to a narrow perspective on specific service characteristics, but not on the entire service process. Therefore, a service-dominant perspective is essential in the value creation of manufacturers, placing relevant service phases in the foreground. However, the process-related character of services is rarely considered in the literature. For this purpose, this study provides a taxonomy that classifies services based on phases. In addition to a systematic literature analysis, this study builds on practical insights by conducting eight expert interviews. The applicability and usefulness of the taxonomy is then demonstrated through exemplary application based on a case study, enabling practitioners to adopt a phase-oriented perspective on digital servitization.
\end{abstract}

\section{Introduction}

For more than three decades, the transition to service-oriented business models in the manufacturing industry has been scientifically discussed under the domain of servitization [1]. Several studies [2-4] have found a link between manufacturers' economic success and their shift to service-oriented value creation. This transformation is closely linked to the digitalization of both the service offerings as well as the entire organization [5]. With data-driven services, such as condition monitoring, predictive maintenance or process optimization, the customer's installed base is supplemented by numerous added value propositions.
These advanced services represent essential building blocks for complex business models and industrial product-service systems (IPSS), such as operator or pay per $x$ models [6]. The required changes in context of so-called digital servitization [2] pose major challenges for many manufacturers, leading to service and digitalization paradoxes that can be observed [7]. The service paradox describes, that "it appears more difficult for firms to make incremental profits by adding services than might be expected" [8]. The digital paradox also indicates, that the "investment to procure and develop digital assets have rarely been paid off yet" [7]. Overall, it can be stated that the development of IPSS, reflecting stages of digital servitization [6], is fraught with various pitfalls linked to a lack of service perspective. Gebauer et al. [9] identify numerous traps, including that manufacturers focus too much on technical possibilities instead of relationships or customer needs. However, the shift to service-oriented business models leads to complex IPSS, "blurring the borderline between product and service" [10]. As a result, increasing process orientation goes hand in hand with digital servitization [5]. Nevertheless, a product-oriented view is still widely common, especially in small and medium sized manufacturers (SME) [11]. Although the competitive importance of services is well known, investments in service development are still given secondary priority [12]. Consequently, the perspective on the service process, which later significantly shapes customer interaction and the providers activities, is still seen as a secondary element in the servitization [13].

There is a lack of lightweight tools in the literature that support manufacturers of digital services $[6,14]$, systematizing the complex character of services in a comprehensive manner. Not all service types are accompanied by critical pitfalls as well as high investments. Sousa and da Silveira [15] distinguish 
between basic Services (BAS) and advanced Services (ADS). While BAS describe less complex and conventional types of services (e.g., training or commissioning), ADS represent more complex services, which go hand in hand with a high level of digitalization or process orientation (e.g., remote diagnostics or result-oriented services). An important contribution to digital servitization lies in existing customer relationships via BAS as part of the use phase of machines, which are successively expanded by ADS (e.g., condition monitoring) [16]. Hence, this study focuses on MRO-related services (maintenance, repair, overhaul) of machine manufacturers, which are extended by digital service elements $[13,17]$. Thus, the objective of this contribution is to systematize the service perspective and poses the following research question (RQ):

What are the key dimensions and characteristics of MRO-related services in manufacturing industry in light of digital servitization?

To answer the research question, a taxonomy for industrial services of manufacturers is developed following the well-established development approach by Nickerson et al. [18]. The aim of the taxonomy is to identify relevant dimensions and characteristics of industrial services. The development is conducted through the lens of the service-dominant logic (SDL), that places the service aspect in the center of the economic value creation [19]. Besides a systematic literature review, the development approach includes expert interviews with a total of eight manufacturers, ensuring its usefulness and applicability. The article is structured as follows: After the introduction, section 2 provides insight into the relevant theoretical foundations. Section 3 discusses the research design in detail and introduces the development of the taxonomy. In section 4, the final dimensions and their characteristics are described. Then, section 5 demonstrates an exemplary application of the taxonomy based from insights of a case study of a machine manufacturer. Finally, section 6 discusses the conceptual contributions, practical implications and limitations of this study.

\section{Theoretical background}

\subsection{Service-phases in manufacturing industry through the lens of Service Dominant Logic}

Manufacturers are increasingly transforming to service-based value creation and thus entering process-oriented relationships with customers and value creation partners as co-creators. In an industrial context, the term service refers to intangible offerings co-created by manufacturers or specialized service providers and its customer. [20] Manufacturers are therefore increasingly converging on the fundamental premises of the SDL, which basically state that all economic exchanges are based on services [19], that are defined as "the application of specialized competences through deeds, processes, and performances for the benefit of another entity or the entity itself' [21]. Supplementary, in the literature, three constitutive dimensions have emerged, interpreting services as a system [22]: performance outcome, performance potential, and performance process $[13,23]$. Whereas the performance outcome "ether increases the customer value related to a material good, or the value contribution in a core value creation process (or value stream) of the customer" [24], the performance potential describes maintaining the ability to perform the service [23]. Thus, a performance potential requires an availability of operational resources, being in line with the SDL. Following the SDL, the performance process thereby takes place in a co-creation in which different entities interact with each other, exchanging skills and knowledge in form of services [19]. In context of this, the SDL describes material goods as "distribution mechanisms for service provision" and operational resources as "the fundamental source of strategic benefit" [19]. Considering these premises, it can be stated that there is a lack of approaches in the literature, which systematically describe the industrial service creation of a manufacturer [13]. Galipoglu and Wolter [25] explain this by pointing to the "heterogeneity of the subject area and the associated difficulty in making statements about the entire spectrum of industry-related services, as well as the different ways in which the supply of industry-related services affects different factors".

However, the systematization of industrial services is valuable, as it supports the design of service activities or the identification of relevant resources [25]. Preliminary work by Kallenberg [22], Gajewski [26], Schuh et al. [13], Winkelmann and Luczak [27] or Frank et al. [28] provide first approaches to this systematization. Kallenberg focuses on the central service functions in successive phases with the help of a framework [22]. For this, a service process typical for manufacturers is proposed, which serves as the foundation for further service research [e.g. 27, 29, 30]. Gajewski [26] models after-sales services using a reference process and proposes similar phases of service provision. Schuh et al. [13] refer to this prior work and cluster MRO services processes into three groups in order to derive a digital twin for industrial services. Frank et al. [28] develop a reference process for smart service businesses, including an overarching perspective from planning and development to 
performing and billing of services. Summarizing, a structure by service phases in chronological order simplifies the systematization of activities, which can include: service inquiry, service clarification, plan and control service, execute service, invoice service $[13,22,26]$. In each of these phases, different activities and characteristics shape the relationship between stakeholders and their value creation.

\subsection{Digital Servitization}

Baines and Lightfoot describe servitization as "the process of transforming manufacturers to compete through services integrated with their products" [20]. In this context, digitalization allows "new ways of value creation" [7]. Therefore it is an important enabler for advanced and service-oriented value propositions of manufacturers, which describes "the convergence of servitization and digitalization" [7]. Thus, this convergence has been discussed in detail for the last few years under the term digital servitization [2, 5, 31]. Due to "inter-dependencies between the immanent product and service shares and the involved persons" [32], IPSS are closely related to digital servitization, representing certain states of a service-oriented transformation strategy. The emergence of information and communication technologies (ICT) enables "increased clientprovider interaction and the 'capture' of customer needs" [5]. However, Coreynen et al. note that there is an insufficient knowledge base on the extent to which manufacturers can leverage the potential of digital servitization [5]. Manufacturers have to consider both the front-end digitalization visible to the customer and the back-end perspective, e.g. operant digital resources [33]. The back-end digitalization required for advanced services and the capabilities and resources linked to service processes, often receive little attention in the early stage of service innovation [34]. This is critical, because according to the SDL, these operational resources are the "fundamental source of strategic benefit" [19] and thus of every servicerelated action.

\subsection{Taxonomies of services in manufacturing industry}

For the analysis of complex phenomena, taxonomies offer a possibility of systematization [18]. Similar approaches such as classifications or typologies are often used synonymously with taxonomies [18]. Wemmerlöv states that "all activities inside an organisation are classifiable" [35]. Building on this statement, we utilize a taxonomy systematizing the service process of manufacturers. According to
Schuh et al., "existing literature does not focus on the phase of service performance" [13], i.e. the servicerelated activities of manufacturers. The authors of this study agree on this conclusion, despite some preliminary work using phase-based reference models (see section 2.1.). Nevertheless, there are some taxonomies emerging from the Information Systems research domain providing a first orientation.

Williams et al. develop a digital service design taxonomy classifying services with regard to the business model, the degree of interaction, and the technology [36]. Rühmann classifies services using a typology and derives different design variants based on characteristics [37]. Paukstadt et al. focus on a smart service taxonomy, which emphasizes the service concept, execution, and monetization [38]. The taxonomy for data-driven services by Azkan et al. adopts a similar perspective and broadens the lens in terms of analytic characteristics and integration of platforms from the business model perspective [39]. Passlick et al. focus on internet of things enabled predictive maintenance services. The classification is based on business models, which includes value promise, payment model or customers [40]. Hunke et al. also address the potential of digitalization and develop a taxonomy to systematize the usage of dataand analytic-based services [41]. Mittag et al. propose an approach based on ten building blocks, e.g. product monitoring or provide information [42] to support the planning of product-related services. Koldewey et al. provide a framework that draws on 20 functionality patterns for smart services [43]. This selection of studies shows that existing taxonomies focus on systematizing specific service types (e.g., characteristics of a data-driven service) as a classifiable object in a performance outcome perspective (see section 2.1.). There is a lack of approaches that systematize the performance process itself. Nevertheless, this perspective is necessary because a service-centric view is inherently relationship-oriented [19]. Thus, the characteristics of the service process must be considered.

\section{Research design and development}

\subsection{Methodology}

As a form of classification, taxonomies provide a basis for future research by systematizing complex phenomena [44]. For developing and evaluating the taxonomy, this contribution draws on the design science research (DSR) methodology [45], as it aims to overcome current limitations of explaining realworld phenomena by building and evaluating sociotechnical artifacts [46]. Thus, the build-evaluate 
pattern by Sonnenberg and Vom Brocke is adapted [47], structuring the following process in two phases.

Regarding an adequate methodology for building the taxonomy, this study adapts the well-established approach of Nickerson et al. [18]. The main goal of this contribution's taxonomy is to classify manufacturers' industrial service processes based on the degree of digital servitization. Thereby, building the taxonomy is conducted through the lens of SDL, considering the interest of practitioners to map relevant aspects of digitalization, as well as the interaction with customers and partners as co-creators. In line with Nickerson et al. [18], we followed an iterative methodology, combining a conceptual-toempirical and an empirical-to-conceptual approach. For the conceptual path we conducted a systematic literature analysis according to Vom Brocke et al. [48] to identify existing work and relevant dimensions as well as characteristics. Within the empirical path, semi-structured interviews were conducted with experts from eight manufacturers of different sizes and branches (see Table 2), following guidelines by Myers and Newman [49]. Sonnenberg and Vom Brocke propose two evaluation activities within a DSR process: ex post evaluation and ex ante evaluation [47]. The interviews are part of the ex ante evaluation, as they were conducted during the design process by empirical identifying relevant dimensions and characteristics. The ex post evaluation is based on an exemplary application of the taxonomy, presented through insights of a case study [50].

\subsection{Taxonomy development}

To develop the taxonomy, several iterations are performed until so-called objective and subjective end conditions are fulfilled [18]. The first iteration is specifying the overarching goal by the definition of meta-dimensions (MD). Since the goal of the taxonomy is to map the service process of manufacturers, this study follows Kallenberg's reference model as conceptual-to-empirical approach [22]. This reference model is adopted as preliminary work in further publications proving its applicability [e.g. 27, 29, 30] and has also been utilized by the authors in previous workshops with industry partners in a research project, that confirmed the usefulness. To enhance conciseness, we modified the proposed service phases resulting in five meta-dimensions: 1) service initiation, 2) inquiry and service clarification, 3) service planning \& control, 4) service execution, 5) service invoicing. The second iteration is also based on a conceptual-to-empirical approach. In order to identify relevant dimensions for the five MD and existing preliminary work, a systematic literature analysis was conducted, guided by Vom Brocke et al. [48]. The databases Scopus, Sciencedirect and AISel were utilized to identify existing classification approaches for industrial service processes. Thus, we developed following search term, which entails related concepts and synonyms through concept-mapping in context of our research scope [48]: ("taxonom*" OR "morphol*" OR "classification") AND ("process*" OR "phase*") AND "manufact*" AND "service*". The search focused on publications from the last 10 years (2010 - 2021) and was limited to title, abstract and keywords, leading to 616 results (see Table 1). Based on title, abstract and keywords we evaluated the results and filtered duplications, resulting in 32 publications.

Table 1. Literature analysis within 2 nd iteration

\begin{tabular}{|c|c|c|}
\hline Database & Total Results & $\begin{array}{c}\text { Relevant } \\
\text { (w/o duplicates) }\end{array}$ \\
\hline Scopus & 494 & 27 \\
\hline AISel & 10 & 1 \\
\hline ScienceDirect & 112 & 4 \\
\hline \multicolumn{2}{|c|}{ Forward \& Backward search } & 12 \\
\hline \multicolumn{2}{|c|}{ Total relevant articles } & 44 \\
\hline
\end{tabular}

Further, a forward and backward analysis to add highly cited preliminary work results in 12 additional articles. The systematic literature analysis leads to a total number of 44 relevant articles. The third iteration follows the empirical-conceptual approach to improve the usefulness and applicability of the taxonomy. Systematic interviews were conducted with experts from German manufacturers (see Table 2).

Table 2. Overview of the interviewed experts

\begin{tabular}{|c|c|c|c|}
\hline & Manufacturer & Size & Interviewed Expert(s) \\
\hline 1 & $\begin{array}{l}\text { Special machinery } \\
\text { manufacturing }\end{array}$ & Med. & Managing Director \\
\hline 2 & $\begin{array}{l}\text { Equipment for heat } \\
\text { treatment }\end{array}$ & Small & Technical manager \\
\hline 3 & $\begin{array}{l}\text { Intralogistics and } \\
\text { conveyor systems }\end{array}$ & Large & $\begin{array}{l}\text { Director Digital } \\
\text { Transformation } \\
\end{array}$ \\
\hline 4 & \begin{tabular}{|c|}
$\begin{array}{c}\text { Brakes, clutches and } \\
\text { system solutions }\end{array}$ \\
\end{tabular} & Med. & $\begin{array}{c}\text { Chief Technical Officer, } \\
\text { Head of marketing }\end{array}$ \\
\hline 5 & $\begin{array}{l}\text { Pumps and pump } \\
\text { systems }\end{array}$ & Large & $\begin{array}{c}\text { Head of service solution } \\
\text { management }\end{array}$ \\
\hline 6 & $\begin{array}{c}\text { Plant systems for oil } \\
\text { and chemical industry }\end{array}$ & Small & Managing Director \\
\hline 7 & $\begin{array}{c}\text { Tools and lasers for } \\
\text { manufacturing }\end{array}$ & Large & Service Specialist \\
\hline 8 & $\begin{array}{c}\text { Filling and packaging } \\
\text { systems }\end{array}$ & Large & $\begin{array}{c}\text { Director Technical } \\
\text { Support Service }\end{array}$ \\
\hline
\end{tabular}

Based on specific practical or experimental knowledge, experts are able to structure and interpret a concrete field of action in a meaningful way [51]. Since the taxonomies purpose is to address manufacturers to classify their industrial service process, expert interviews are valuable for empirical 
development. We selected the companies based on size and prior analysis regarding the current service portfolio (offering of basic and advanced services) to achieve a heterogeneous coverage within the empirical development path of the taxonomy. The classification of companies into the sizes Small, Medium and Large is based on the EU definition regarding the number of employees (Small: <50, Medium: <250, Large: $>=250$ ) [52]. The interviews were conducted in May and June 2021 over video conferencing systems. The length of each interview ranged from 1 to 1.5 hours. The first author guided the interviews, while a coauthor conducted a simultaneous protocol [53], allowing a direct interpretation of the statements [51]. In addition, all interviews were recorded. Initially, general information were obtained during the interviews, e.g., the expert's position within the manufacturing company. In order to enable the experts to evaluate and expand individual dimensions and characteristics, the taxonomy was presented afterwards. After conducting four interviews, the taxonomy was modified based on the experts feedback by readjusting few dimensions and combining several characteristics. Within a fourth iteration, a second set of four interviews was conducted and no further adjustments were required to the taxonomy. The experts confirmed the applicability and usefulness (subjective criteria according to Nickerson et al. [18]). In addition, all objective criteria [18] were fulfilled, meaning that no further iteration was necessary.

\section{Taxonomy for industrial service phases}

This chapter describes the final taxonomy in detail (see Table 3). Thereby, it answers the formulated $\mathbf{R Q}$, which dimensions and characteristics are required for the classification of service processes in manufacturing industry. The taxonomy consists of five meta-dimensions (MD) and a total of 14 dimensions. In addition to each dimension, the right column shows whether a characteristic is exclusive $(\mathrm{E})$ or non-exclusive $(\mathrm{N})$. In total, the taxonomy has 49 characteristics, capable of individually describing a manufacturer's service process.

MD 1 - Service initiation: The first MD describes the service initiation and consists of the two dimensions Event and Initiator. The triggering Event can be based on conventional activities, such as Manual identification of demand by the customer, Periodic execution, e.g., via maintenance contracts or periodic updates, or via the equipment itself through Automatic service notifications [42, 44]. More complex events are continuous Analyses of historical order data to forecast possible demand [39]. Drawing on this, Usage-, process- or condition-based data can be analyzed, e.g., to identify a need for service via condition monitoring systems. Manufacturers with extensive knowledge of specific wear characteristics leverage this information for Predictive analysis, scheduling maintenance services based on predicted wear conditions of the manufacturing system [40]. Related to the first dimension, the Initiator dimension depends on the degree of digitalization and connectivity of the co-creators. Thus, the characteristics are Customer, Provider, or the machine System itself. Thus, the machinery is not merely an operand resource, but rather, using ICT, becoming increasingly an operant resource [44].

MD 2 - Inquiry and service clarification: The second MD describes inquiry capture and service clarification consisting of four dimensions: Customer interface, Internal system support, Information availability, and Requirement formulation. Typically, the Customer interface is based on personal contact via Face-to-face, phone or e-mail [54]. Web-based digital formats such as web forms or an app can also be used as a manual communication channel, as well as a Real time chat function. More complex solutions can be offered via Digital interfaces (e.g., API, connected ERP system) [42]. Some manufacturers have also been offering Platform solutions allowing customers to make inquiries or configure products via self-service portals [39]. The dimension Internal system support describes the type of digital processing by the provider [42]. Typically, smaller manufacturers do not have a standardized system, but work with Paper based and/or digital documents (e.g., Word, Excel). More support is provided by Database-driven systems, such as customer relationship management systems, which are supplemented by other software. The experts consider an Integrated service management system as an ideal and transparent solution, combining all systems and thus eliminating media discontinuities. The highest level of integration uses an additional Ticket system tracking servicerelevant activities and customer contacts. The Information availability dimension describes data accessibility during service clarification [55] and is based on three characteristics: Master data and service history, Knowledge database, and Real-time process/condition data. In addition to the basic information of the first characteristic, providers using a Knowledge database can identify problem-solving patterns, which assist in improving the service clarification process. Furthermore, access to Real-time process/condition data from the customer's system supports fault identification. The dimension Requirement formulation is a crucial influencing factor for targeted service processing. 
Table 3. Taxonomy of industrial service phases

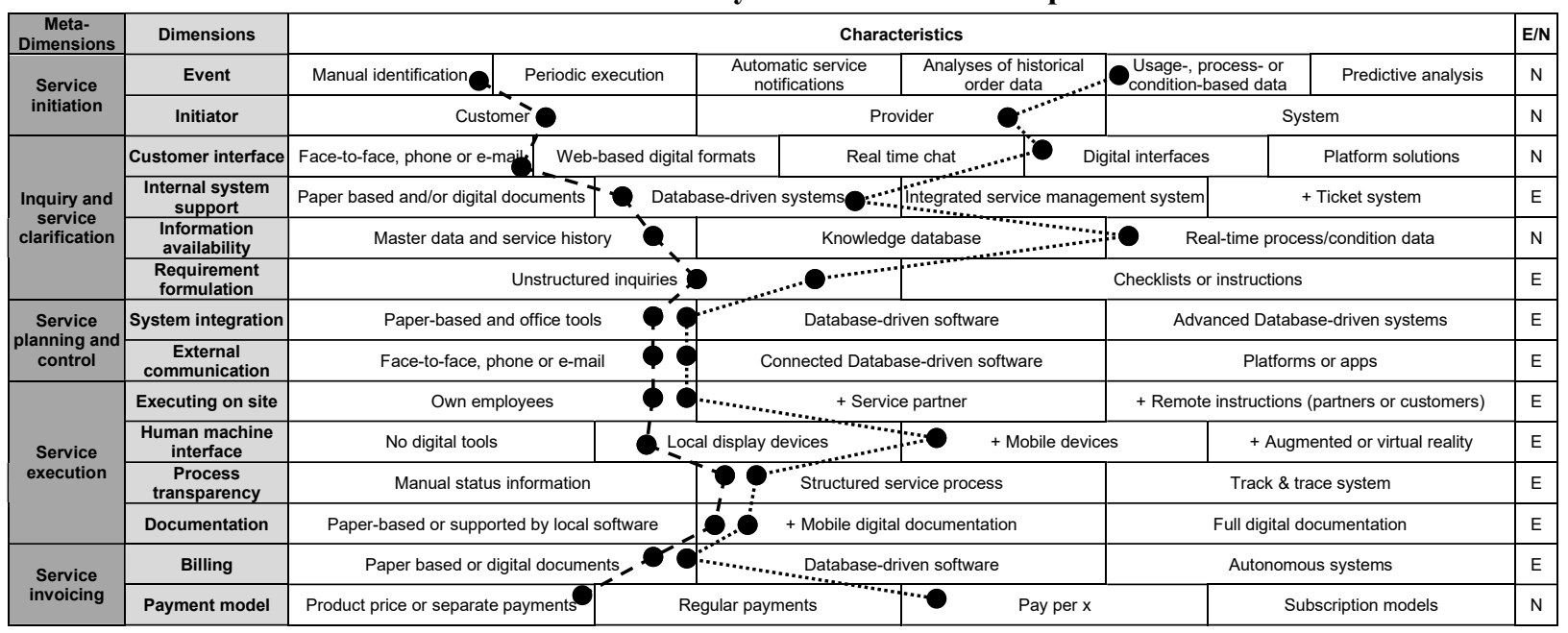

Unstructured inquiries might lead to a time intensive clarification process due to several subsequent queries [56]. Customers should be assisted in formulating requirements by Checklists or instructions.

MD 3 - Service planning and control: The third MD describes the planning and control phase, including two dimensions: System integration, and External communication. Independently of the second MD, manufacturers operate with different systems in the planning and controlling phase. Therefore, the first dimension System integration consists of three characteristics: Paper-based and office tools, Database-driven Systems and Advanced Databasedriven Systems. Small companies with few employees often plan and control their operations Paper-based or with standard office tools, e.g., Excel. For more complex structures, a Database-driven system is utilized to avoid non-transparent processes [55]. Advanced database-driven Systems enable employees to manage capacity planning more efficiently through support functions, e.g., by automatically considering the responsibility or even the capabilities of the service personnel [22]. The standard for External communication with co-creators is the personal contact via Face-to-face, phone or e-mail. In the case of suppliers, logistics service providers or other longterm customer or partner relationships, a Connected Database-driven software (e.g., a connected ERP) accelerates the communication and value co-creation process [54]. Another option is offered by Platforms or apps for exchanging order data and coordinating (e.g., delivery) schedules.

MD 4 - Service execution: Under Service execution, the main service activities visible to the customer on site are provided. Thus, the dimension Executing on site is differentiated from the responsibility of services which are performed on the customer's machine [57]. The provider's Own employees perform the service itself, and/or a Service partner collaborates with the provider. In addition, customers or other co-creators may be enabled to conduct services themselves via Remote instructions from the provider. The Human machine interface (HMI), providing service personnel with digital information, is another service-relevant factor. While conventional services operate with $\mathrm{No}$ digital tools, machines equipped with microelectronics enable information via Local display devices. A more advanced stage is represented by Mobile devices, enabling additional support functions, such remote access to ERP database or condition data of the manufacturing system [58]. In addition, Augmented or virtual reality functions (e.g., data glasses) provide extensive information. As the service provision is often linked to narrow deadlines and high requirements, Process transparency and the ability to provide information regarding the current processing status are essential. Here, Manual status information can be mentioned first. Customers might request the processing status by phone, which may lead to higher costs due to unsystematic processes in the organization. Based on a Structured service process, the provider tracks status information efficiently and communicates the status via phone or e-mail. The third characteristic describes an automated Track \& trace system enabling the customer to query the processing status independently [42]. Following the service execution, Documentation is an important part of the provider-customer (and co-creators) relationship, also forming the basis for invoicing. Basically, Paperbased or supported by local software (e.g., office tools, scans, etc.) documentation is commonly used. Increased efficiency is achieved through Mobile documentation (e.g., via tablet), which is then directly created on-site by service personnel. The documents are either processed later in-house or transmitted via mobile internet. A Full digital documentation in line 
with a centralized database enables consistent and transparent management of relevant information and eliminates media discontinuities.

MD 5 - Service invoicing: In the context of the dimension Service invoicing, the performed activities are processed and charged to the customer. For this purpose, in the dimension Billing, manufacturers use Paper-based or digital documents applying conventional office tools. Database-driven software enables the invoicing process to be more efficient. In the context of increasing network-based value creation and Autonomous systems, automated processing via smart contracts is also becoming increasingly interesting and therefore represents the final characteristic. The dimension Payment model varies depending on the manufacturer's service portfolio and customer's needs [40]. Services within the Product price or separate payments are billed via individual invoices. In the case of maintenance contracts or software licenses, Regular payments are made. More complex solutions represent pay per $x$ models, in which payments are made per product produced or based on availability. Subscription models represent the configuration of specific functions, which customers add or cancel within their contract, resulting into regular time-based payments [38].

\section{Exemplary taxonomy application}

The majority of taxonomies draw on case studies for building or demonstrating their applicability [59]. Thus, this section classifies empirical objects to illustrate the relevance and usefulness of the final taxonomy [18], based on insights of a case study conducted between September 2020 and May 2021. The case study is based on a manufacturer, representing many companies facing digital servitization. Besides the close collaboration in a research project, we carried out several workshops with the service manager and service technicians. As allowing an in-depth view on complex phenomena [50], the conducted case study gave detailed insights into the service process and the manufacturers business model. These insights allow systematizing the current and targeted service process of the focused manufacturer within the final taxonomy. The selected machine manufacturer offers mobile equipment, that is used by customers in context of welding for subsequent heat treatment. As an SME, the manufacturer is currently retrofitting its equipment with edge-devices to achieve connectivity. Initially this is to improve the efficiency of conventional MRO services. In the future, advanced services based on remote access are planned, enabled by the transmission of status or usage data. The taxonomy in
Table 3 visualizes the current service process by a dashed line. The targeted service process, enabled by the retrofitting approach, is represented by a dotted line. The motivation of the manufacturer lies in infrequently occurring failures of the mobile equipment, but depending on the location, these failures could lead to high consequential costs for the customer. Additionally, the conventional interaction via phone and e-mail as well as the frequent need for on-site services to identify faults are disrupting the flow of information and complicating the service process in general. The mobile machines are equipped with microelectronics, which is sufficient to estimate the next maintenance operation for certain components based on process data. This data can be transmitted via edge-device as new digital interface to the manufacturer. As a service provider, the manufacturer is able to initiate a maintenance service or to deliver spare parts at an early stage. For this purpose, new software must be integrated in the inquiry and service clarification phase, which makes the status and process information available to the service staffs. As the enhancement of the communication to the customer is linked to further investments and the added value of the new databased approaches is to be tested first, external communication will initially remain conventional. However, the manufacturer can proactively contact the customer and is sufficiently informed regarding the condition of the machine due to the machine data, improving the service clarification. During the service execution phase, the manufacturer considers mobile devices as useful since relevant data is available on site. Thus, existing devices, which are used for documentation, must be supplemented with this functionality. Currently, services are either included in the warranty or billed separately. After successful implementation, in the future the manufacturer plans a usage-based payment as pay per x model, enabled by leveraging machine data via permanent data interface.

In summary, the presented taxonomy allows the classification of service processes. As a result, it encourages early service development (e.g., digitalization, use of new technology) while focusing on the entire service process.

\section{Discussion, Implications and Further Research}

As the value creation of manufacturers shifts to relationship-based, long-term customer interactions, product-oriented business models are losing their dominance. Thus, services and a strong processoriented organization have become increasingly crucial. While literature consents to the importance of 
digital servitization, there is a lack of lightweight approaches to service development addressing the phase-oriented nature of services [13]. This study addresses this research gap by presenting a taxonomy based on a structured conceptual and empirical development process. The involvement of industry through interviews, as well as the demonstration of applicability, underline the methodological soundness and relevance of the study results. As managerial implications, the taxonomy presented in this study provides an applicable tool for classifying services based on relevant service phases. This approach supports practitioners to identify those service-related aspects affected by the integration of digital technologies. The discussions with the experts during the interviews show that the taxonomy leads to an active reflection of the existing service process. Thus, the practical application of the taxonomy directs attention to necessary adjustments along the service process at an early stage. Using this knowledge, appropriate actions or a roadmap for service development can be derived. In addition, practitioners should examine why and to what extend the Customer interface differs in their characteristics to External communication, i.e., with all partners, co-creators, and thus customers. Since these dimensions address different phases of the service process, a separate consideration is valuable. However, it is noticeable that the characteristics at the Customer interface within the Inquiry and service clarification phase offer different options than those in External communication within the phase of Service planning and control. A reason for this might be different isolated solutions of the co-creators in a value network, preventing a standardized communication culture. In the long term, synergy effects could be leveraged if appropriate standards were utilized. Regarding conceptual implications, the taxonomy represents a substantiated result of a conceptual and empirical development approach. The study lays a basis for further research to systematize and understand the nature of services and process orientation in context of digital servitization. Researchers will be able to distinguish manufacturers based on their various approaches to performing services in the future and highlight any differences in order to derive success factors. This study is subject to limitations. The resulting taxonomy reflects only a temporal snapshot of reality. Especially due to dynamics in information and communication technologies, regular updating of the dimensions and characteristics is necessary. The adopted research methodology in this study is based on both literature analysis and empirical research. Nevertheless, a comprehensive representation of all possible instantiations of service processes cannot be fully guaranteed. As a result, depending on the use case, further adjustments may be required. Lastly, a taxonomy is always influenced by the scientists that conducted the development process. Other researchers, using the same methods but with different scientific background and interests, might associate some dimensions and characteristics differently and thus influence the result of the taxonomy. A potential avenue for further research is the derivation of archetypes, enriched with further information of the companies, which were captured during the interviews. Furthermore, the practitioners stressed the interest regarding results of the other manufacturers analyzed and what resources and transformation strategies they implement. Thus, the analysis of successful transformations, enabling factors in digital servitization and its systematization might be a promising opportunity for further research. Due to the focus on the service process itself and for the sake of compactness [18], the final taxonomy excludes other relevant aspects that do not directly address the constitutive service dimension of performance process. In this context, the influences of both internal and external factors should be examined in more detail. As discussed in chapter 2.1, the necessary performance potential must be available to execute the service processes. Therefore, these organizational resources must be aligned with the service processes in line with digital servitization [60]. While a manufacturer can continue to digitalize internally, some dimensions of the taxonomy depend heavily on customers or partners (co-creators). This impacts the offering of digital services, e.g., if the customers do not grasp the added value of pay per $\mathrm{x}$ payment models or a supplier declines database-driven approaches as external communication interface. Thus, these dependencies regarding the performance potential that significantly influence the performance process and the combination with this study's taxonomy represent a potential avenue for further research.

\section{Acknowledgment}

This research is funded by the German Federal Ministry of Education and Research (BMBF, funding code: 02K18D130) and implemented by the Project Management Agency Karlsruhe (PTKA).

\section{References}

[1] Sandra Vandermerwe and Juan Rada, "Servitization of Business: Adding Value by Adding Services", 1988.

[2] Kohtamäki, M., V. Parida, P.C. Patel, and H. Gebauer, "The relationship between digitalization and 
servitization: The role of servitization in capturing the financial potential of digitalization", Technological Forecasting and Social Change, 2020.

[3] Dachs, B., S. Biege, M. Borowiecki, G. Lay, A. Jäger, and D. Schartinger, "Servitisation of European manufacturing: evidence from a large scale database", The Service Industries Journal, 34(1), 2014, pp. 5-23.

[4] Kreyenborg, A., M. Austerjost, and M. Groll, "A WebCrawling Based Study on Servitization: Analysis of Service Offerings by German Manufacturers of Machinery and Equipment", ECIS 2021 Research Papers, 61. https://aisel.aisnet.org/ecis2021_rp/61

[5] Coreynen, W., P. Matthyssens, and W. van Bockhaven, "Boosting servitization through digitization: Pathways and dynamic resource configurations for manufacturers", Industrial Marketing Management, 60, 2017, pp. 42-53.

[6] Lay, G., ed., Servitization in Industry, Springer International Publishing, Cham, 2014.

[7] Gebauer, H., M. Paiola, N. Saccani, and M. Rapaccini, "Digital servitization: Crossing the perspectives of digitization and servitization", Industrial Marketing Management, 93, 2021, pp. 382-388.

[8] Neely, A., "Exploring the financial consequences of the servitization of manufacturing", Operations Management Research, 1(2), 2008, pp. 103-118.

[9] Gebauer, H., E. Fleisch, C. Lamprecht, and F. Wortmann, "Growth paths for overcoming the digitalization paradox", Business Horizons, 2020, pp. 313-323.

[10] Goedkopp, M.J., C. van Halen, H. te Riele, and P. Rommens, Product Service systems: Ecological and Economoc Basics, 1999.

[11] Rapaccini, M., F. Adrodegari, N. Saccani, C. Barbieri, and R. Giannetti, "DIGITAL SERVITIZATION OF SMES: THE ROLE OF KNOWLEDGE-INTENSIVE BUSINESS SERVICES(KIBS)", Spring Servitization Conference 2020, 2020, 2020, pp. 81-87.

[12] Roos, G., "Servitization as Innovation in Manufacturing-A Review of the Literature", in The Handbook of Service Innovation, R. Agarwal, W. Selen, G. Roos, and R. Green, Editors. 2015. Springer London: London.

[13] Schuh, G., P. Jussen, and T. Harland, "The Digital Shadow of Services: A Reference Model for Comprehensive Data Collection in MRO Services of Machine Manufacturers", Procedia CIRP, 73, 2018, pp. 271-277.

[14] Rondini, A., J. Matschewsky, G. Pezzotta, and M. Bertoni, "A simplified approach towards customer and provider value in PSS for small and medium-sized enterprises", Procedia CIRP, 73, 2018, pp. 61-66.

[15] Sousa, R. and G.J. da Silveira, "Capability antecedents and performance outcomes of servitization", International Journal of Operations \& Production Management, 37(4), 2017, pp. 444-467.

[16] Porter, M.E. and J.E. Heppelmann, "How Smart, Connected Products are Transforming Companies", in Harvard Business Review. 2015.

[17] Schroeder, A., P. Naik, A.Z. Bigdeli, and T. Baines, "IoT enabled advanced services: exploring the IoT artefact as a socio-technical construct", 25th Annual EurOMA conference, 24-26th June 2018. Hungary.

[18] Nickerson, R.C., U. Varshney, and J. Muntermann, "A method for taxonomy development and its application in information systems", European Journal of Information Systems, 22(3), 2013, pp. 336-359.

[19] Vargo, S.L. and R.F. Lusch, "Institutions and axioms: an extension and update of service-dominant logic", Journal of the Academy of Marketing Science, 44(1), 2016, pp. 5-23.

[20] Baines, T. and H. Lightfoot, Made to serve: How manufacturers can compete through servitization and product service systems, Wiley, Chichester, West Sussex, 2013.

[21] Vargo, S.L. and R.F. Lusch, "Evolving to a New Dominant Logic for Marketing", Journal of Marketing, 68(1), 2004, pp. 1-17.

[22] Kallenberg, R., Ein Referenzmodell für den Service in Unternehmen des Maschinenbaus, Aachen, 2002.

[23] Schermann, M., Risk Service Engineering: Informationsmodelle für das Risikomanagement, 1st edn., Gabler Verlag / Springer Fachmedien Wiesbaden GmbH Wiesbaden, Wiesbaden, 2011.

[24] Schuh, G. and P. Stüer, "Framework for Lean Management in Industrial Services", in Advances in production management systems: Competitive manufacturing for innovative products and services; IFIP WG 5.7 International Conference, APMS 2012, Rhodes, Greece, September 24-26, 2012; revised selected papers, C. Emmanouilidis, M. Taisch, and D. Kiritsis, Editors. 2013. Springer: Heidelberg.

[25] Galipoglu, E. and M. Wolter, "Typologien industrienaher Dienstleistungen: Eine Literaturübersicht", in Smart Service Engineering: Konzepte und Anwendungsszenarien für die digitale Transformation, O. Thomas, M. Nüttgens, and M. Fellmann, Editors. 2017. Springer Gabler: Wiesbaden.

[26] Gajewski, T., Referenzmodell zur Beschreibung der Geschäftsprozesse von After-Sales-Dienstleistungen unter besonderer Berücksichtigung des Mobile Business, HNI, Paderborn, 2004.

[27] Winkelmann, K. and H. Luczak, "Modelling, simulation and prospective analysis of cooperative provision of industrial services using coloured Petri nets", International journal of simulation, 7(1473$804 x), 2006$, pp. 10-26.

[28] Frank, M., J. Gausemeier, N. Hennig-Cardinal von Widdern, C. Koldewey, J.S. Menzefricke, and J. Reinhold, "A reference process for the Smart Service business: development and practical implications", Proceedings of the International Society for Professional Innovation Management (ISPIM), 2020.

[29] Matijacic, M., G. Däuble, M. Fellmann, D. Özcan, M. Nüttgens, and O. Thomas, "Informationsbedarfe und bereitstellung in technischen Serviceprozessen: Eine Bestandsaufnahme unterstützender IT-Systeme am Point of Service", Proceedings Multikonferenz der Wirtschaftsinformatik, 2014, pp. 2035-2047.

[30] Daeuble, G., D. Oezcan, C. Niemoeller, M. Fellmann, M. Nuettgens, and O. Thomas, "Information Needs of the Mobile Technical Customer Service - A Case Study 
in the Field of Machinery and Plant Engineering", in 48th Hawaii International Conference on System Sciences (HICSS), 2015, Kauai, Hawaii.

[31] Lerch, C. and M. Gotsch, "Digitalized Product-Service Systems in Manufacturing Firms: A Case Study Analysis", Research-Technology Management, 58(5), 2015, pp. 45-52.

[32] Meier, H., R. Roy, and G. Seliger, "Industrial ProductService Systems-IPS 2", CIRP Annals, 59(2), 2010, pp. 607-627.

[33] Pawar, K.S., A. Beltagui, and J.C. Riedel, "The PSO triangle: designing product, service and organisation to create value", International Journal of Operations \& Production Management, 29(5), 2009, pp. 468-493.

[34] Michalik, A., F. Möller, M. Henke, and B. Otto, "Towards utilizing Customer Data for Business Model Innovation: The Case of a German Manufacturer", Procedia CIRP, 73, 2018, pp. 310-316.

[35] Wemmerlöv, U., "A Taxonomy for Service Processes and its Implications for System Design", International Journal of Service Industry Management, 1(3), 1990, pp. 20-40.

[36] Williams, K., S. Chatterjee, and M. Rossi, "Design of emerging digital services: a taxonomy", European Journal of Information Systems, 17(5), 2008, pp. 505517.

[37] Rühmann, N., Empirische Entwicklung einer Typologie für Gestaltungsvarianten der Serviceproduktion im Maschinenbau, Shaker, 2008.

[38] Paukstadt, U., G. Strobel, and S. Eicker, "UNDERSTANDING SERVICES IN THE ERA OF THE INTERNET OF THINGS: A SMART SERVICE TAXONOMY", ECIS 2019 Research Papers.

[39] Azkan, C., L. Iggena, I. Gür, F. Möller, and B. Otto, "A Taxonomy for Data-Driven Services in Manufacturing Industries", PACIS 2020 Proceedings. 184., 2020.

[40] Passlick, J., S. Dreyer, D. Olivotti, L. Grützner, D. Eilers, and M.H. Breitner, "Predictive maintenance as an internet of things enabled business model: A taxonomy", Electronic Markets, 2020.

[41] Hunke, F., C. Engel, R. Schüritz, and P. Ebel, "Understanding the Anatomy of Analytics-Based Services - a Taxonomy to Conceptualize the Use of Data and Analytics in Services", (ECIS 2019)..

[42] Mittag, T., M. Rabe, T. Gradert, A. Kühn, and R. Dumitrescu, "Building blocks for planning and implementation of smart services based on existing products", Procedia CIRP, 73, 2018, pp. 102-107.

[43] Koldewey, C., M. Meyer, P. Stockbrügger, R. Dumitrescu, and J. Gausemeier, "Framework and Functionality Patterns for Smart Service Innovation", Procedia CIRP, 91, 2020, pp. 851-857.

[44] Herterich, M.M., T. Buehnen, F. Uebernickel, and W. Brenner, "A Taxonomy of Industrial Service Systems Enabled by Digital Product Innovation", in 2016 49th Hawaii International Conference on System Sciences (HICSS).

[45] Peffers, K., T. Tuunanen, C. Gengler, and M. Rossi, "THE DESIGN SCIENCE RESEARCH PROCESS: A MODEL FOR PRODUCING AND PRESENTING INFORMATION SYSTEMS RESEARCH", 2006.
[46] Hevner, A. and S. Chatterjee, eds., Design Research in Information Systems: Theory and Practice, Springer Science+Business Media LLC, Boston, MA, 2010.

[47] Sonnenberg, C. and J. Vom Brocke, "Evaluations in the Science of the Artificial - Reconsidering the BuildEvaluate Pattern in Design Science Research", in Design Science Research in Information Systems. Advances in Theory and Practice, D. Hutchison, T. Kanade, J. Kittler, et al. Editors. 2012, Berlin

[48] Vom Brocke, J., A. Simons, B. Niehaves, B. Niehaves, K. Reimer, R. Plattfaut, and A. Cleven, "RECONSTRUCTING THE GIANT: ON THE IMPORTANCE OF RIGOUR IN DOCUMENTING THE LITERATURE SEARCH PROCESS", ECIS 2009 Research Papers

[49] Myers, M.D. and M. Newman, "The qualitative interview in IS research: Examining the craft", Information and Organization, 17(1), 2007, pp. 2-26.

[50] Yin, R.K., Case study research and applications: Design and methods, SAGE, Sixth Edition, 2018.

[51] Vogel, D. and B.J. Funck, "Immer nur die zweitbeste Lösung? Protokolle als Dokumentationsmethode für qualitative Interviews", Forum Qualitative Sozialforschung, 19(1), 2018.

[52] https://ec.europa.eu/growth/smes/business-friendlyenvironment/sme-definition_en, accessed 12-19-2019.

[53] Bogner, A., B. Littig, and W. Menz, Interviews mit Experten: Eine praxisorientierte Einführung, Springer VS, Wiesbaden, 2014.

[54] Lukas, M., Quantitative Bewertung von Standardisierung für Ausführungsprozesse im Industrieservice, 1st edn., Apprimus Verlag, Aachen, 2019.

[55] Wang, Y., A. Faath, T. Goerne, and R. Anderl, "Development of a Toolbox for Engineering in Project Teams for Industrie 4.0", International MultiConference of Engineers and Computer Scientists, 14-16 March, 2018, 2018.

[56] Sames, G. and J. Lapa, "Stand der Digitalisierung von Geschäftsmodellen zu Industrie 4.0 im Mittelstand: Ergebnisse einer Umfrage bei Unternehmen", 2020.

[57] Thomas, O., P. Walter, N. Blinn, and M. Schlicker, "ITsupported value-added chains for the integration of products and services", International Journal of Internet Manufacturing and Services, 2(1), 2009, p. 43.

[58] Anderl, R. and J. Fleischer, Leitfaden Industrie 4.0: Orientierungshilfe zur Einführung in den Mittelstand, VDMA Forum Industrie, Frankfurt a.M., 2015.

[59] Herterich, M.M., M. Holler, F. Uebernickel, and W. Brenner, Understanding the Business Value: Towards a Taxonomy of Industrial Use Scenarios enabled by Cyber-Physical Systems in the Equipment Manufacturing Industry, 2015.

[60] C. Koldewey, J. Gausemeier, N. Chohan, M. Frank, J. Reinhold, and R. Dumitrescu, "Aligning Strategy and Structure for Smart Service Businesses in Manufacturing", in 2020 IEEE International Conference on Technology Management, Operations and Decisions (ICTMOD). 